\title{
Attacking postoperative metastases using perioperative oncolytic viruses and viral vaccines
}

\author{
Lee-Hwa Tai ${ }^{1}$ and Rebecca Auer ${ }^{1,2 *}$ \\ ${ }^{1}$ Centre for Innovative Cancer Research, Ottawa Hospital Research Institute, Ottawa, ON, Canada \\ 2 Department of Surgery, University of Ottawa, Ottawa, ON, Canada
}

\author{
Edited by: \\ Philippe Fournier, DKFZ, Germany \\ Reviewed by: \\ Volker Schirrmacher, DKFZ, Germany \\ Zong Sheng Guo, Harvard University, \\ USA

\section{*Correspondence:} \\ Rebecca Auer, Ottawa General \\ Hospital, 1617 CCW, Box\#134, 501 \\ Smyth Road, Ottawa, ON K1H8L6, \\ Canada \\ e-mail: rauer@ottawahospital.on.ca
}

Surgical resection of solid primary malignancies is a mainstay of therapy for cancer patients. Despite being the most effective treatment for these tumors, cancer surgery has been associated with impaired metastatic clearance due to immunosuppression. In preclinical surgery models and human cancer patients, we and others have demonstrated a profound suppression of both natural killer (NK) and T cell function in the postoperative period and this plays a major role in the enhanced development of metastases following surgery. Oncolytic viruses (OV) were originally designed to selectively infect and replicate in tumors, with the primary objective of directly lysing cancer cells. It is becoming increasingly clear, however, that OV infection results in a profound inflammatory reaction within the tumor, initiating innate and adaptive immune responses against it that is critical for its therapeutic benefit. This anti-tumor immunity appears to be mediated predominantly by NK and cytotoxic T cells. In preclinical models, we found that preoperative OV prevents postoperative NK cell dysfunction and attenuates tumor dissemination. Due to theoretical safety concerns of administering live virus prior to surgery in cancer patients, we characterized safe, attenuated versions of $\mathrm{OV}$, and viral vaccines that could stimulate NK cells and reduce metastases when administered in the perioperative period. In cancer patients, we observed that in vivo infusion with oncolytic vaccinia virus and ex vivo stimulation with viral vaccines promote NK cell activation. These preclinical studies provide a novel and clinically relevant setting for OV therapy. Our challenge is to identify safe and promising OV therapies that will activate $\mathrm{NK}$ and $\mathrm{T}$ cells in the perioperative period preventing the establishment of micrometastatic disease in cancer patients.

Keywords: metastasis, postoperative period, oncolytic viruses, viral vaccines, cancer, perioperative immunostimulation, natural killer cells, surgical stress

\section{SURGICAL STRESS PROMOTES THE FORMATION OF METASTASES}

Surgical resection is the mainstay of therapy for most solid malignancies but, even with complete resection, many patients harbor microscopic residual disease and ultimately die of a recurrence (1). Our group $(2,3)$ and others have clearly demonstrated, using different animal and tumor models, that surgery promotes the formation of metastatic disease (4-11) and the number of metastatic deposits is directly proportional to the magnitude of surgical stress $(6,12)$. In clinical studies, a complicated postoperative course correlates with inferior cancer survival and increased incidence of metastases $(13,14)$. A number of perioperative changes have been proposed to explain the promotion of metastases formation following surgery including (1) dissemination of tumor cells during the surgical procedure (15-20), (2) local and systemic release of growth factors, such as vascular endothelial growth factor (VEGF) $(21,22)$, and (3) cellular immune suppression. The cellular immune suppression following major surgery appears to peak at 3 days (23) following surgery but may persist for weeks $(7,23-25)$. It is hypothesized to be mediated by secretion of stress hormones, such as glucocorticoids $(26,27)$, catecholamines $(27-$ 29), and prostaglandins (26). It is characterized by both plasma cytokine changes [a decrease in IL-2 (30), IL-12 (31) and an increase IL-6 (27, 30, 32, 33), IL-10 (34)] and a decrease in the number and function of circulating lymphocytes [cytotoxic T cells (35), dendritic cells (DC) (36) and natural killer (NK) cells $(2,3,37)]$.

The postoperative stress response represents a diverse set of physiological changes that have evolved to ensure that the host can heal following major tissue trauma. These changes, however, involve pathways and mediators that can be exploited by cancer cells to facilitate metastatic spread. While a number of correlative studies have demonstrated an association between some of these changes and the enhanced formation of metastases following surgery, few mechanistic studies have been undertaken to understand it. This review will focus on the importance of both innate and adaptive postoperative cellular immune suppression, specifically $\mathrm{NK}$ and cytotoxic $\mathrm{T}$ cell postoperative dysfunction and make the case for the use of preoperative oncolytic viruses $(\mathrm{OV})$ and viral vaccines to prevent the promotion of cancer metastases following surgery.

\section{SURGICAL STRESS INHIBITS NK CELL FUNCTION AND ANTIGEN-SPECIFIC CD8 ${ }^{+}$T CELL FUNCTION}

Both the innate and adaptive immune system play a significant role in anti-tumor immunity. As integral members of the innate immune system, NK cells are involved in the direct killing of cells 
displaying abnormalities linked to infection, malignancy, or transplantation $(38,39)$. Immunosurveillance of the host by NK cells for malignant cells results in direct cytotoxicity and the production of cytokines to enhance the immune response (39).

Natural killer cell dysfunction following surgery, as measured in a standard [51-Cr]-release assay, has been documented in both human patients $(3,25,40-42)$ and animal models $(3,5,7,40,41$, 43). Postoperative NK cell suppression correlates with increased metastases in animal models of spontaneous $(3,9)$ and implanted $(3,10,11)$ metastases, while in human studies low NK activity during the perioperative period is associated with a higher rate of cancer recurrence and mortality in a number of different cancer types (44-46). Despite the large number of studies that have documented postoperative NK cell dysfunction, very few studies have thoroughly characterized and directly explored the mechanism of this suppression $(9,11,47)$. Our laboratory has clearly defined a role for NK cells in the development of postoperative metastases (2). Using several reproducible mouse models of surgical stress, including B16 melanoma, CT26 colon cancer and 4T1 breast cancer, our laboratory has demonstrated a consistent and significant (two- to fourfold) increase in the formation of experimental and spontaneous pulmonary metastases following surgery. In these experimental models, surgery markedly reduced NK cell total numbers in the spleen and affected NK cell migration. Further, ex vivo and in vivo tumor cell killing by NK cells were significantly reduced in surgically stressed mice. To establish that NK cells play the crucial mediating role in clearing tumor metastases following surgery, we transferred surgically stressed NK cells into NK-deficient mice (IL-2 $\gamma$ R-knock out) and observed enhanced lung metastases in tumor-bearing mice compared to mice who received untreated NK cells (3). Transfer of NK cells labeled with the NK specific marker DX5 from surgically stressed and no surgery control donors into naive recipient mice represents the first in vivo evidence that links surgery to the spread of cancers via NK cells (3). In human studies, we have also confirmed that postoperative cancer surgery patients had markedly reduced NK cell cytotoxicity (3).

The adaptive immune system and more specifically $\mathrm{CD} 8^{+} \mathrm{T}$ cells responses have received the majority of the attention from the cancer immunity field. Of recent interest in our lab is the impact of surgical stress on the development and maintenance of an acquired $\mathrm{T}$ cell-mediated anti-tumor immune response. A global reduction in $\mathrm{T}$ cell numbers and function post-surgery has been documented in preclinical studies and cancer patients (35). However, the effects of tumor-associated antigen (TAA)-specific $\mathrm{T}$ cells have not been evaluated and represent a current focus of research interest in our lab.

\section{POSTOPERATIVE CELLULAR IMMUNE SUPPRESSION IS REVERSIBLE}

Fortunately postoperative immune suppression is reversible, so while the postoperative period provides a window of opportunity for cancer cells to metastasize and grow, it also provides a window of opportunity to intervene, by supporting or further stimulating the immune system, and, in doing so, attenuate the development of cancer recurrences $(48,49)$. Based on promising preclinical results $(8,50,51)$, clinical trials of preoperative non-specific immune stimulation with low-dose recombinant IFN $\alpha$ (52) or IL-2 (5358) have demonstrated less NK and T cell suppression following surgery. In two randomized studies of patients undergoing resection of colorectal cancer (CRC) primary tumors (58) and hepatic metastases (57), preoperative low-dose subcutaneous (s.c.) IL-2 was associated with an improved prognosis. In the first study, 86 CRC patients with stage II or III disease were randomized to receive low-dose IL-2 twice a day for 3 consecutive days prior to surgery or no preoperative treatment. At a median follow-up of 54 months, there were significantly few recurrences in the IL-2 group (21.4 vs. $43.1 \%, p=0.03$ ) and a trend toward improved overall survival (OS). In the second study, 50 CRC patients with Stage IV disease, undergoing curative or palliative surgery, were randomized to the same two treatment arms. The median progression-free survival (PFS) and OS were significantly longer in the preoperative IL-2 group. While these studies were not designed to evaluate cancer outcomes, a Phase II trial in 120 patients undergoing resection for renal-cell carcinoma has demonstrated a significant improvement in 5-year PFS with preoperative IL-2 (74 vs. $62 \%, p=0.02$ ) (54). Moreover, in all of these studies, preoperative IL-2 was safe and well tolerated with adverse events limited to pyrexia (Grade IIII). A few other non-conventional immunomodulators have been evaluated for their ability to boost cellular immunity in the perioperative period including cimetidine $(59,60)$, mistletoe extract $(61$, 62), and granulocyte colony-stimulating factor (GMCSF) (63). Despite the paucity, the data are promising and perioperative treatment strategies, aimed at stimulating the cellular immune system warrants further study. As outlined in the remainder of this review, OV are an attractive agent to reverse perioperative immune suppression.

\section{WHY USE PERIOPERATIVE ONCOLYTIC VIRUSES FOR IMMUNE STIMULATION? A MULTIPRONGED APPROACH FOR A MULTIFACTORIAL PROBLEM}

Oncolytic viruses are not considered a "traditional" immunotherapy but their multiple mechanisms of action provide several advantages over traditional cytokine immune stimulants in the complex postoperative period. First, the immune stimulation provided by an OV is a more "physiological" immune stimulus, engaging and maturing DC, which in turn activates NK and T cells. The multitude of cytokines and chemokines, stimulate the appropriate picomolar concentration, by a systemic virus infection would be impossible to replicate even with the most carefully designed cytokine cocktail. Second, the OV will selectively replicate in and kill residual cancer cells, providing a direct cytolytic effect to remaining micrometastases, but also delivering the immune response to the tumor selectively. Finally, there is strong rationale to hypothesize that OV could infect and replicate better in the postoperative state because of the surge of growth factors such as VEGF, providing a therapeutic advantage for OV in postoperative cancer patients.

\section{PRECLINICAL EVIDENCE FOR NK CELL ACTIVATION WITH PERIOPERATIVE ONCOLYTIC VIRUSES}

Viruses, in general, are known to activate NK cells $(64,65)$ and $\mathrm{OV}$ are no exception. One of the first reports to support the anti-tumor activation of NK cells in response to OV therapy was 
reported by Diaz et al. in which depletion experiments were performed to demonstrate that B16 melanoma tumor regression was achieved in $\mathrm{a} \mathrm{CD8}^{+} \mathrm{T}$ and NK cell-dependent manner following vesicular stomatitis virus (VSV) intratumoral (i.t.) injection (66). Supporting these findings, oncolytic Reovirus treatment of prostate cancer produced an anti-tumor $\mathrm{CD}^{+} \mathrm{T}$ cell response along with prominent NK cell infiltration $(67,68)$. Miller et al. also observed that i.t. therapy with oncolytic herpes simplex virus (HSV) for B16 melanoma was abrogated in syngeneic models lacking NK and T cell subsets (69). In mechanistic studies with oncolytic new castle disease virus (NDV), Jarahian et al. demonstrated enhanced NK cytotoxicity against human tumor cell lines infected with NDV. Further, soluble receptor binding and blocking assays suggest that NKp44 and NKp46 recognition of viral ligand hemagglutinin-neuraminidase on NDV infected tumor cells mediated NK anti-tumor activity (70). We have demonstrated that oncolytic ORF virus (ORFV) has a profound effect on NK cells following i.v. delivery and that this NK cell activation is the main mechanism by which ORFV exerts its anti-tumor effect (71). It is very likely that stimulation of NK cells play an important role in the therapeutic effect of many OV, not only by enhancing NK cell-mediated killing of tumor target cells but also by triggering a robust, T cell-mediated, anti-tumor immune response (72).

Given that surgery suppresses NK cell activity and OV activate NK cells, we explored the ability of preoperative OV to prevent postoperative NK cell suppression, and in turn prevent the development of postoperative metastases. Using our established murine model of surgical stress, we demonstrated that perioperative administration of novel oncolytic ORF and vaccinia viruses can reverse NK cell suppression following surgery and this correlates with a reduction in the postoperative formation of metastases (3). Similar effects were observed in 4T1-tumor bearing surgically stressed mice treated with perioperative OV. When NK cells were depleted, the effect was no longer present, suggesting that suppression of tumor metastases in a surgical stress model is mainly mediated through OV activation of NK cells and subsequent NK cell-mediated tumor lysis (3).

We demonstrated a similar effect with the novel oncolytic rhabdovirus, Maraba (MG1) and used this model to explore the mechanism of NK cell activation further. MG1 is a double mutant rhabdovirus with deletion in the $G$ and $M$ proteins (73). It is a clinical candidate OV that is scheduled to begin a Phase I clinical trial in 2014. MG1 infection in immune competent mice resulted in an immediate $(24 \mathrm{~h})$ and intense activation of NK cells, as evidenced by significantly increased NK cell cytotoxicity and cytokine secretion. Moreover, preoperative i.v. administration of MG1 overcame surgery-induced NK suppression and attenuated the development of postoperative metastases in the B16lacZ model of implanted lung metastases, as well as in the breast $4 \mathrm{~T} 1$ model of spontaneous lung metastases (74).

Mechanistically, we demonstrated that MG1 activates NK cells through conventional DC ( $\mathrm{CDC}$ ) (Figure 1). Using an ex vivo $\mathrm{NK}$ :DC co-culture system, we showed lack of NK infection, activation, and cytotoxicity in the absence of cDC. Further, in cDC ablated mice (CD11c-Diphtheria Toxin Receptor Transgenic mice), NK cell cytotoxicity was significantly reduced following MG1 administration (74). While we demonstrated that MG1 does not directly infect or activate NK cells, this is not the case for other OV. For instance, vaccinia virus has been shown to interact directly with NK cells through Toll-like-receptor-(TLR)-2 (75).

As the interplay between OV and immune cells in the perioperative period is critically important for the eradication of tumors, we further explored these interactions in our preclinical models of tumor and surgical stress. In both B16 melanoma and 4T1 breast tumor models, we observed postoperative expansion of myeloidderived suppressor cells (MDSC) (3), which are known regulatory cells that have been shown to expand following various pathologies to suppress innate and adaptive immunity (76-80). The role of MDSC on surgery-induced dysfunction of NK cells and antigenspecific $\mathrm{T}$ cells and its potential interaction with $\mathrm{OV}$ is part of ongoing research in our lab (Figure 1).

\section{PRECLINICAL EVIDENCE OF TAA-SPECIFIC T CELL ACTIVATION WITH PERIOPERATIVE ONCOLYTIC VACCINE}

Oncolytic vaccines (OVax) are OV that express TAA that can direct the host immune response toward the TAA while simultaneously performing viral oncolysis and creating an inflammatory tumor microenvironment $(81,82)$. Dr. Brian Lichty has pioneered this prime-boost OVax platform and demonstrated remarkable efficacy in the B16 model (82-86). B16 cells express the TAA, dopachrome tautomerase (DCT), which is a protein involved in melanogenesis and is present in normal melanocytes and melanoma. As previous studies have demonstrated, Ad-DCT is able to prime a DCT specific T cell immune response and protect mice from a B16 tumor challenge or tumor re-growth $(87,88)$, but has limited efficacy in a therapeutic model of lung metastases (89). Dr. Lichty's group engineered MG1, to express DCT upon productive infection and used these two viruses in a prime-boost strategy in tumor-bearing animals. They found that when Ad-DCT was allowed to prime an immune response, followed 9 days later by an MG1-hDCT boost, the results were remarkable, leading to a significant reduction in lung metastases with durable cures in $>20 \%$ of mice, something not seen when MG1 expressing an irrelevant transgene (MG1-GFP, green-fluorescent protein) was used. Strikingly, $\sim 27 \%$ of $\mathrm{CD}^{+} \mathrm{T}$ cells were directed against DCT. Selective depletion of cytotoxic T lymphocytes (CTL) at the time of the boost abrogates the therapeutic efficacy, underscoring their central role. In the near and longer term, we will focus on using OVax, such as MG1-DCT in preclinical mouse tumor models of surgical stress to perioperative boost adaptive immune functions.

\section{CLINICAL EXPERIENCE WITH PERIOPERATIVE OV IN CANCER SURGERY PATIENTS}

The compelling preclinical and clinical data with oncolytic vaccinia virus, in particular the evidence that it can stimulate a potent anti-tumor immune response (90) led us to hypothesize that perioperative treatment with this OV could improve recurrence-free survival following surgical resection. We designed a single center Phase II clinical trial where patients with metastatic colorectal tumors within the liver were treated with a single i.v. dose of oncolytic vaccinia virus prior to surgical resection (91). This trial explored the mechanisms of action of oncolytic vaccinia virus through a series of correlative blood and tissue studies collected from patients pre- and post-OV treatment and surgery. In this 


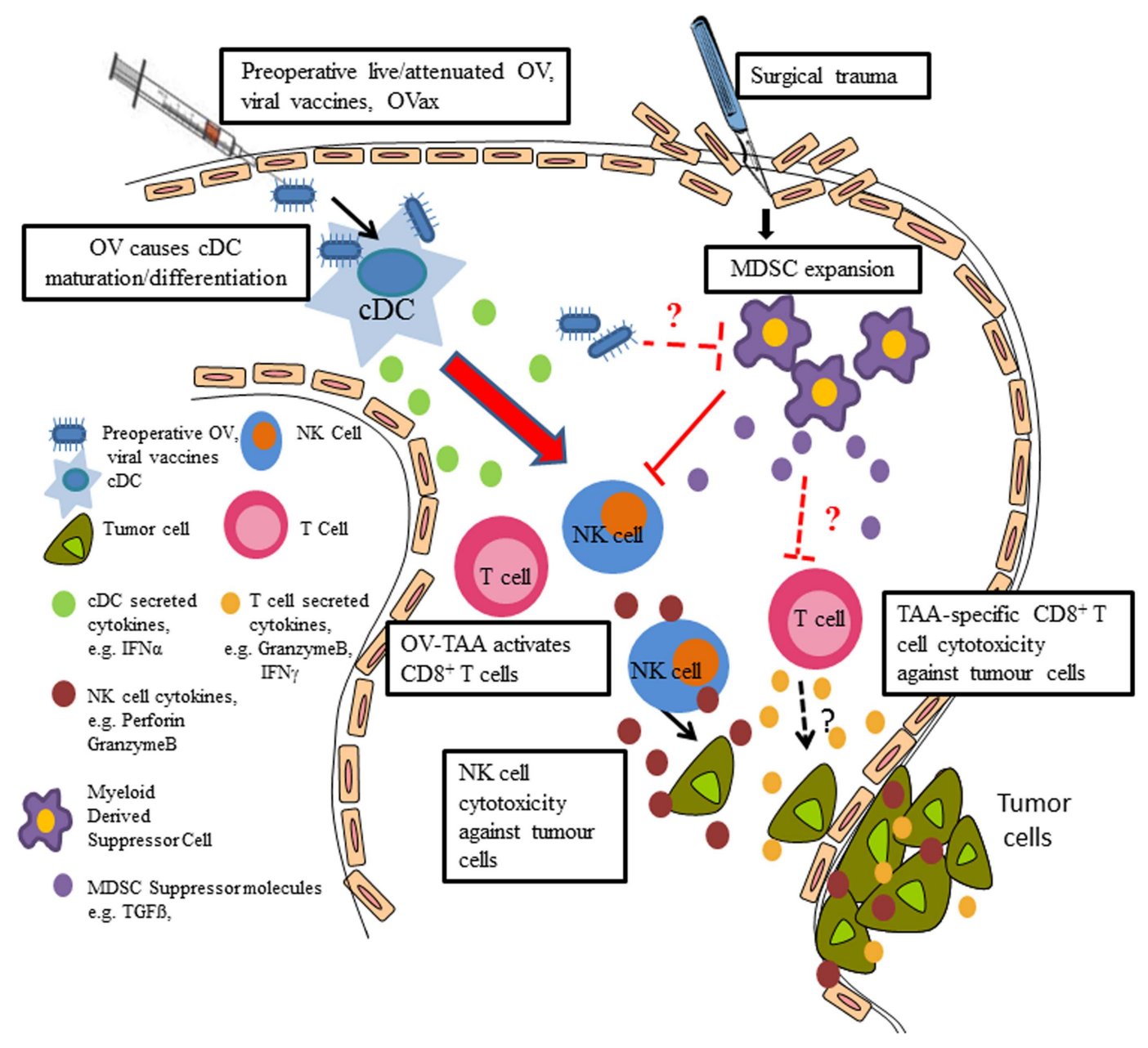

FIGURE 1 | Preoperative delivery of live/attenuated OV, viral vaccines, and oncolytic vaccines enhances innate and adaptive immune cell function to reduce postoperative metastatic disease. Preoperative administration of the live or attenuated OV results in NK cell activation via $\mathrm{CDC}$; preoperative delivery of viral vaccines results in IFN $\alpha$ production (likely through $\mathrm{CDC}$ ), which results in NK cell activation, thereby preventing surgery-induced dysfunction and removal of tumor cell emboli and micrometastases in the postoperative period. Postoperative MDSC expansion contributes to NK cell dysfunction and OV may reverse the suppressive effects of MDSC. Preoperative oncolytic vaccines may activate tumor antigen-specific $\mathrm{CD} 8^{+} \mathrm{T}$ cells and reduce tumor burden and increase survival. study, we confirmed that NK cell cytotoxicity improved in the setting of pre-operative oncolytic vaccinia virus compared to baseline control blood (3). Further, we detected genome copies of vaccinia virus in the tumors of patients following resection (unpublished data), which suggests that viral targeting of the tumor by i.v. injection may elicit an immune response in the tumor. These results demonstrated for the first time that oncolytic vaccinia virus markedly increases NK activity in cancer surgery patients.

In the same patient population of CRC, systemic delivery of oncolytic reovirus prior to planned surgical resection of liver metastases was undertaken by researchers in the UK (92) In this "window of opportunity" trial of 10 patients, Adair et al. was able to recover live reovirus from the blood cells, but not from plasma removed from these patients. In addition, reovirus protein was identified preferentially in resected tumor tissue, but not in normal liver tissue. Their results suggest that immune cells in the blood may protect virus from neutralizing antibodies, thus providing targeted delivery of OV to tumors. Importantly, preoperative treatment with oncolytic reovirus was well tolerated, with the most common side effects being flu-like symptoms and no reported grade 3 or 4 toxicities in any patients (92). In a study of perioperative oncolytic HSV delivery, virus was injected intratumorally preand post-surgical resection into patients with recurrent glioblastoma multiforme (93). Evidence of immune cell infiltration and viral replication in the resected tumors was reported by the authors. Notably, no patients developed HSV related encephalitis or required antiviral treatment (93). In a series of clinical trials using NDV-modified autologous tumor cell vaccine (NDVATV) for treatment of colorectal, renal cell, and glioblastoma cancer patients, researchers detected a significantly improved survival advantage compared to unvaccinated and historical controls. However, NDV-ATV was mostly administered postoperatively and 
not preoperatively to prevent surgery-induced immunosuppression, which might further improve upon the survival advantage. Similar to the above studies, NDV-ATV was well tolerated, with the most common side effects being mild-fever/headache and no associated autoimmunity (70, 94-99). These reports demonstrate the feasibility of perioperative $\mathrm{OV}$ administration into cancer surgery patients.

\section{THE IMPORTANCE OF TIMING FOR OV ADMINISTRATION IN THE PERIOPERATIVE PERIOD}

While the postoperative period provides a window of opportunity for cancer cells to metastasize and grow, it also provides a window of opportunity to intervene, by strengthening the immune system and reducing recurrence of cancer following surgery in cancer patients. In our preclinical perioperative vaccine studies, we hypothesized that neoadjuvant delivery of vaccine immediately prior to surgery will allow for maximal NK cell stimulation to counteract surgery-induced NK cell suppression $(100,101)$. Indeed, we observed that influenza vaccine administered on the same day, immediately prior to surgery, reduced metastases most effectively. The results from NK cells isolated from cancer surgery patients also confirm that the timing of influenza administration is critical for its effect. In four out of four cancer surgery patients, NK cells isolated prior to surgical resection demonstrated enhanced cytotoxicity and IFN $\gamma$ secretion following ex vivo pulsing with influenza vaccine, while in only one of these patients was similar activation demonstrated in NK cells isolated 1 day following surgery, suggesting that surgery-induced NK cell dysfunction can be prevented but not reversed by influenza. In humans receiving a flu shot as part of a vaccination campaign, NK cell activation peaked at 1-2 days following immunization (101). Based on this, it appears that a cancer vaccination strategy is probably best delivered the day before cancer surgery, in order to allow sufficient time to maximally activate NK cells prior to surgical stress.

Equally important for a replicating virus is the growth advantage that the postoperative state may provide, increasing oncolysis, viral replication, and spreading. Surgical stress results in a surge of VEGF with resulting angiogenesis to facilitate wound healing (21). Kottke et al. $(102,103)$ have previously demonstrated that a VEGF surge improved viral replication, viral cell lysis, and an innate immune mediated attack, in particular by NK cells, by allowing tumor-associated endothelial cells to transiently support viral replication during the VEGF surge. The sequential combination of oncolytic vaccinia virus and the small molecule B-raf and VEGF inhibitor, sorafenib, has also demonstrated efficacy in preclinical models and a few patients (104), further supporting the concept that OV and VEGF may act synergistically if the timing of viral administration is considered.

\section{BARRIERS TO PERIOPERATIVE OV THERAPY AND STRATEGIES TO OVERCOME THEM}

While these data are exciting, the perioperative use of $\mathrm{OV}$ is in preclinical and early stages of clinical investigation. In the design of our preoperative OV trial, we were confronted with multiple concerns associated with the use of a live virus immediately prior to surgery in cancer patients. In particular, concerns were raised about the potential for an overwhelming postoperative systemic inflammatory response, the risk of spread to members of the operating room team, and risk of meningitis with epidural analgesia. These safety concerns present real barriers to the development of perioperative OV. In their recent publication, Adair et al. demonstrated the feasibility and safety of perioperative live reovirus infusion prior to surgery in CRC patients. However, OV infusion was administered 6-28 days prior to surgery and not immediately before surgery. Further, three patients received fewer than their planned five doses of reovirus. In one patient, this was due to a decline in white blood cell count, while the remaining two patients opted to not receive their last doses of OV prior to surgery because of their own concerns that flu-like symptoms might interfere with the planned surgery, highlighting a strongly held belief that remains a theoretic barrier to immediate preoperative delivery of a replicating virus (92).

Given these very real concerns surrounding live perioperative delivery of $\mathrm{OV}$, we subsequently focused on generating nonreplicating MG1 viruses to characterize their ability to activate NK cells and attenuate metastases in a model of experimental (B16) and spontaneous (4T1) metastases following surgical stress. To accomplish this, we constructed a replication incompetent MG1 MG1-Gless-eGFP, that is only capable of one infectious life cycle, thus offering a safe in vivo profile. Next, we compared these variations of MG1: (1) live MG1-productive infection and replication; (2) a G-less version (MG1-Gless) - capable of a single-replication cycle of virus; (3) MG1 exposed to ultraviolet (UV) for $2 \mathrm{~min}$ to $2 \mathrm{~h}$ - replication incompetent confirmed by plaque assay. MG1, MG1-Gless, and MG1-UV ${ }^{2}$ min exhibited significantly higher NK cell function compared to PBS control, and they effectively attenuated in vivo B16lacZ lung metastases to near identical levels at high viral doses $\left(1 \times 10^{8} \mathrm{PFU}\right)$. However, at all lower doses studied $\left(1 \times 10^{5-7} \mathrm{PFU}\right)$, live MG1 demonstrated better efficacy than attenuated MG1. Furthermore, we characterized this panel of MG1 viruses in terms of virus morphological structure and cell associated interaction via Electron Microscopy, qRT-PCR, and western blot and found that MG1-UV ${ }^{2}$ min remains an intact virus particle (virus proteins, genetic materials) with cell-associated interactions, corresponding to the highest NK cell activation and least lung metastases, among MG1-UV viruses. Importantly, we demonstrated that preoperative i.v. administration of equivalent high doses $\left(1 \times 10^{8} \mathrm{PFU}\right)$ of live and attenuated MG1 (MG1-Gless or MG1-UV ${ }^{2}$ min $)$ overcame surgery-induced NK cell suppression and reduced the development of postoperative metastases in the B16lacZ implanted lung metastases, as well as in the breast 4T1 model of spontaneous lung metastases. Taken together, these results suggest that the intact viral particle and cellular recognition, along with viral proteins and genomic RNA are essential for NK cell-mediated anti-tumor responses. Non-replicating forms of MG1, including MG1-UV ${ }^{2}$ min , are novel cancer therapies that can be safely used in the immediate preoperative period to prevent the formation of metastatic disease (74).

Parallel to our perioperative attenuated OV studies, we assessed a wide range of potential agents to provide perioperative non-specific immunostimulation including TLR ligands and inactivated vaccines against infectious disease. Firstly, we assessed a panel of routinely used immunizations, including vaccines against influenza, meningitis, measles/mumps/rubella, 
diphtheria/tetanus/pertussis/polio, pneumonia, and influenza for their ability to activate (CD69 expression) and enhance NK cell function (cytotoxicity and IFN $\gamma$ secretion). When directly compared, influenza was the most potent NK cell activator among the prophylactic vaccines, although, not unexpectedly, inoculating mice with live replicating viruses (such as vaccinia virus) induced higher levels of NK cell cytotoxicity. Using our mouse models of experimental (B16 melanoma) and spontaneous (4T1) metastases and surgical stress, we subsequently demonstrated that preoperative delivery of a single dose of influenza resulted in a dramatic reduction in lung metastases (101). In order to confirm that NK cells play a mediating role in preventing postoperative metastases following influenza treatment, we pharmacologically depleted NK cells and observed a complete abrogation of the therapeutic effect of influenza vaccination. Furthermore, we discovered that IFN $\alpha$ had the most dramatic increase following influenza vaccination after assessing a panel of serum cytokines following influenza administration. We also observed that low-dose preoperative IFN $\alpha$ was able to rescue surgery-induced NK cell dysfunction and metastases to the same degree as influenza vaccination. The central role for IFN $\alpha$ was underscored by demonstrating that influenza vaccination was not able to increase postoperative NK cell activity or attenuate postoperative metastases in IFN $\alpha$ receptor-deficient mice. In PBMC isolated from human donors, Type I IFN blocking antibody prevented influenza from activating NK cells (101). While our study did not explore the role of DC in the production of IFN $\alpha$ following influenza vaccination, it is very likely that they represent the primary source, resulting in secondary NK cell stimulation (see Figure 1).

\section{CLINICAL IMPLICATIONS AND FUTURE DIRECTIONS}

Surgical resection is the mainstay of therapy for patients with localized solid malignancies. Even with complete resection, many patients develop a metastatic recurrence and ultimately die of their disease. The immediate postoperative period provides an ideal environment for the formation of cancer metastases. Despite this, it remains a therapeutic window that is largely ignored. There are currently no standard perioperative anti-cancer therapies aimed at preventing postoperative metastases. We have demonstrated in preclinical models that perioperative OV therapy can activate both the innate and adaptive immune responses and attenuate metastatic disease. Early clinical trials confirm the feasibility of this strategy but these therapies must be rigorously characterized for safety and efficacy and then translated into thoughtfully designed clinical trials. This research supports the concept that neoadjuvant (preoperative) OV treatments can reverse postoperative immune dysfunction, while directly infecting and killing tumor cells and creating a favorable immune microenvironment. This treatment strategy has the potential to impact countless cancer patients who undergo surgical resection of their solid tumor every year.

\section{REFERENCES}

1. Saxe C. Unlocking the Mysteries of Metastases. (2013). Available from: http://www.cancer.org/cancer/news/expertvoices/post/2013/01/23/unlockingthe-mysteries-of-metastasis.aspx

2. Seth R, Tai LH, Falls T, de Souza CT, Bell JC, Carrier M, et al. Surgical stress promotes the development of cancer metastases by a coagulation-dependent mechanism involving natural killer cells in a murine model. Ann Surg (2013) 258(1):158-68. doi:10.1097/SLA.0b013e31826fcbdb

3. Tai LH, de Souza CT, Belanger S, Ly L, Alkayyal AA, Zhang J, et al. Preventing postoperative metastatic disease by inhibiting surgery-induced dysfunction in natural killer cells. Cancer Res (2013) 73(1):97-107. doi:10.1158/0008-5472. CAN-12-1993

4. Shiromizu A, Suematsu T, Yamaguchi K, Shiraishi N, Adachi Y, Kitano S. Effect of laparotomy and laparoscopy on the establishment of lung metastasis in a murine model. Surgery (2000) 128(5):799-805. doi:10.1067/msy.2000.108047

5. Ben-Eliyahu S, Page GG, Yirmiya R, Shakhar G. Evidence that stress and surgical interventions promote tumor development by suppressing natural killer cell activity. Int J Cancer (1999) 80(6):880-8. doi:10.1002/(SICI)10970215(19990315)80:6<880::AID-IJC14>3.0.CO;2-Y

6. Tsuchiya Y, Sawada S, Yoshioka I, Ohashi Y, Matsuo M, Harimaya Y, et al. Increased surgical stress promotes tumor metastasis. Surgery (2003) 133(5):547-55. doi:10.1067/msy.2003.141

7. Da Costa ML, Redmond P, Bouchier-Hayes DJ. The effect of laparotomy and laparoscopy on the establishment of spontaneous tumor metastases. Surgery (1998) 124(3):516-25. doi:10.1016/S0039-6060(98)70098-4

8. Colacchio TA, Yeager MP, Hildebrandt LW. Perioperative immunomodulation in cancer surgery. Am J Surg (1994) 167(1):174-9. doi:10.1016/0002-9610(94) 90070-1

9. Glasner A, Avraham R, Rosenne E, Benish M, Zmora O, Shemer S, et al. Improving survival rates in two models of spontaneous postoperative metastasis in mice by combined administration of a beta-adrenergic antagonist and a cyclooxygenase-2 inhibitor. J Immunol (2010) 184(5):2449-57. doi:10.4049/jimmunol.0903301

10. Benish M, Bartal I, Goldfarb Y, Levi B, Avraham R, Raz A, et al. Perioperative use of beta-blockers and COX-2 inhibitors may improve immune competence and reduce the risk of tumor metastasis. Ann Surg Oncol (2008) 15(7):2042-52. doi:10.1245/s10434-008-9890-5

11. Goldfarb Y, Sorski L, Benish M, Levi B, Melamed R, Ben-Eliyahu S. Improving postoperative immune status and resistance to cancer metastasis: a combined perioperative approach of immunostimulation and prevention of excessive surgical stress responses. Ann Surg (2011) 253(4):798-810. doi:10.1097/SLA. 0b013e318211d7b5

12. Southall JC, Lee SW, Allendorf JD, Bessler M, Whelan RL. Colon adenocarcinoma and B-16 melanoma grow larger following laparotomy vs. pneumoperitoneum in a murine model. Dis Colon Rectum (1998) 41(5):564-9. doi:10.1007/BF02235261

13. Lerut T, Moons J, Coosemans W, Van Raemdonck D, De Leyn P, Decaluwe H, et al. Postoperative complications after transthoracic esophagectomy for cancer of the esophagus and gastroesophageal junction are correlated with early cancer recurrence: role of systematic grading of complications using the modified Clavien classification. Ann Surg (2009) 250(5):798-807. doi:10.1097/SLA. 0b013e3181bdd5a8

14. Eberhardt JM, Kiran RP, Lavery IC. The impact of anastomotic leak and intra-abdominal abscess on cancer-related outcomes after resection for colorectal cancer: a case control study. Dis Colon Rectum (2009) 52(3):380-6. doi:10.1007/DCR.0b013e31819ad488

15. Sugarbaker EV, Ketcham AS. Mechanisms and prevention of cancer dissemination: an overview. Semin Oncol (1977) 4(1):19-32.

16. Fortner JG. Inadvertent spread of cancer at surgery. J Surg Oncol (1993) 53(3):191-6. doi:10.1002/jso.2930530313

17. Yamaguchi K, Takagi Y, Aoki S, Futamura M, Saji S. Significant detection of circulating cancer cells in the blood by reverse transcriptase-polymerase chain reaction during colorectal cancer resection. Ann Surg (2000) 232(1):58-65. doi:10.1097/00000658-200007000-00009

18. Roberts S, Long L, Jonasson O, Mc GR, Mc GE, Cole WH. The isolation of cancer cells from the blood stream during uterine curettage. Surg Gynecol Obstet (1960) 111:3-11.

19. Foss OP, Brennhovd IO, Messelt OT, Efskind J, Liverud K. Invasion of tumor cells into the bloodstream caused by palpation or biopsy of the tumor. Surgery (1966) 59(5):691-5.

20. Sales JP, Wind P, Douard R, Cugnenc PH, Loric S. Blood dissemination of colonic epithelial cells during no-touch surgery for rectosigmoid cancer. Lancet (1999) 354(9176):392. doi:10.1016/S0140-6736(99)92164-5

21. Belizon A, Balik E, Feingold DL, Bessler M, Arnell TD, Forde KA, et al. Major abdominal surgery increases plasma levels of vascular endothelial growth 
factor: open more so than minimally invasive methods. Ann Surg (2006) 244(5):792-8. doi:10.1097/01.sla.0000225272.52313.e2

22. Pera M, Nelson H, Rajkumar SV, Young-Fadok TM, Burgart LJ. Influence of postoperative acute-phase response on angiogenesis and tumor growth: open vs. laparoscopic-assisted surgery in mice. J Gastrointest Surg (2003) 7(6):783-90. doi:10.1016/S1091-255X(03)00111-2

23. Coffey JC, Wang JH, Smith MJ, Bouchier-Hayes D, Cotter TG, Redmond HP. Excisional surgery for cancer cure: therapy at a cost. Lancet Oncol (2003) 4(12):760-8. doi:10.1016/S1470-2045(03)01282-8

24. Da Costa ML, Redmond HP, Finnegan N, Flynn M, Bouchier-Hayes D. Laparotomy and laparoscopy differentially accelerate experimental flank tumour growth. Br J Surg (1998) 85(10):1439-42. doi:10.1046/j.1365-2168.1998. 00853.x

25. Espi A, Arenas J, Garcia-Granero E, Marti E, Lledo S. Relationship of curative surgery on natural killer cell activity in colorectal cancer. Dis Colon Rectum (1996) 39(4):429-34. doi:10.1007/BF02054059

26. Bessey PQ, Watters JM, Aoki TT, Wilmore DW. Combined hormonal infusion simulates the metabolic response to injury. Ann Surg (1984) 200(3):264-81. doi:10.1097/00000658-198409000-00004

27. Ogawa K, Hirai M, Katsube T, Murayama M, Hamaguchi K, Shimakawa T, et al. Suppression of cellular immunity by surgical stress. Surgery (2000) 127(3):329-36. doi:10.1067/msy.2000.103498

28. Elenkov IJ, Chrousos GP. Stress hormones, proinflammatory and antiinflammatory cytokines, and autoimmunity. Ann N Y Acad Sci (2002) 966:290-303. doi:10.1111/j.1749-6632.2002.tb04229.x

29. Udelsman R, Goldstein DS, Loriaux DL, Chrousos GP. Catecholamineglucocorticoid interactions during surgical stress. J Surg Res (1987) 43(6):539-45. doi:10.1016/0022-4804(87)90128-4

30. Baxevanis CN, Papilas K, Dedoussis GV, Pavlis T, Papamichail M. Abnormal cytokine serum levels correlate with impaired cellular immune responses after surgery. Clin Immunol Immunopathol (1994) 71(1):82-8. doi:10.1006/ clin. 1994.1055

31. Ahlers O, Nachtigall I, Lenze J, Goldmann A, Schulte E, Hohne C, et al. Intraoperative thoracic epidural anaesthesia attenuates stress-induced immunosuppression in patients undergoing major abdominal surgery. Br J Anaesth (2008) 101(6):781-7. doi:10.1093/bja/aen287

32. Wlaszczyk A, Adamik B, Durek G, Kubler A, Zimecki M. Immunological status of patients subjected to cardiac surgery: serum levels of interleukin 6 and tumor necrosis factor alpha and the ability of peripheral blood mononuclear cells to proliferate and produce these cytokines in vitro. Arch Immunol Ther $\operatorname{Exp}$ (Warsz) (1996) 44(4):225-34.

33. Nakazaki H. Preoperative and postoperative cytokines in patients with cancer. Cancer (1992) 70(3):709-13. doi:10.1002/1097-0142(19920801)70:3<709: :AID-CNCR2820700328>3.0.CO;2-O

34. Whitson BA, D'Cunha J, Maddaus MA. Minimally invasive cancer surgery improves patient survival rates through less perioperative immunosuppression. Med Hypotheses (2007) 68(6):1328-32. doi:10.1016/j.mehy.2006.09.063

35. Bartal I, Melamed R, Greenfeld K, Atzil S, Glasner A, Domankevich V, et al. Immune perturbations in patients along the perioperative period: alterations in cell surface markers and leukocyte subtypes before and after surgery. Brain Behav Immun (2010) 24(3):376-86. doi:10.1016/j.bbi.2009.02.010

36. Ho CS, Lopez JA, Vuckovic S, Pyke CM, Hockey RL, Hart DN. Surgical and physical stress increases circulating blood dendritic cell counts independently of monocyte counts. Blood (2001) 98(1):140-5. doi:10.1182/blood.V98.1.140

37. Greenfeld K, Avraham R, Benish M, Goldfarb Y, Rosenne E, Shapira Y, et al. Immune suppression while awaiting surgery and following it: dissociations between plasma cytokine levels, their induced production, and NK cell cytotoxicity. Brain Behav Immun (2007) 21(4):503-13. doi:10.1016/j.bbi.2006.12.006

38. Lanier LL. NK cell receptors. Annu Rev Immunol (1998) 16:359-93. doi:10. 1146/annurev.immunol.16.1.359

39. Lanier LL. NK cell recognition. Annu Rev Immunol (2005) 23:225-74. doi:10. 1146/annurev.immunol.23.021704.115526

40. Pollock RE, Lotzova E, Stanford SD. Mechanism of surgical stress impairment of human perioperative natural killer cell cytotoxicity. Arch Surg (1991) 126(3):338-42. doi:10.1001/archsurg.1991.01410270082013

41. Pollock RE, Lotzova E, Stanford SD. Surgical stress impairs natural killer cell programming of tumor for lysis in patients with sarcomas and other solid tumors. Cancer (1992) 70(8):2192-202. doi:10.1002/1097-0142(19921015)70: $8<2192:: A I D-C N C R 2820700830>3.0 . C O ; 2-6$
42. Lukomska B, Olszewski WL, Engeset A, Kolstad P. The effect of surgery and chemotherapy on blood NK cell activity in patients with ovarian cancer. Cancer (1983) 51(3):465-9. doi:10.1002/1097-0142(19830201)51:3<465: :AID-CNCR2820510318>3.0.CO;2-9

43. Page GG, Blakely WP, Ben-Eliyahu S. Evidence that postoperative pain is a mediator of the tumor-promoting effects of surgery in rats. Pain (2001) 90(12):191-9. doi:10.1016/S0304-3959(00)00403-6

44. Tartter PI, Steinberg B, Barron DM, Martinelli G. The prognostic significance of natural killer cytotoxicity in patients with colorectal cancer. Arch Surg (1987) 122(11):1264-8. doi:10.1001/archsurg.1987.01400230050009

45. Schantz SP, Brown BW, Lira E, Taylor DL, Beddingfield N. Evidence for the role of natural immunity in the control of metastatic spread of head and neck cancer. Cancer Immunol Immunother (1987) 25(2):141-8. doi:10.1007/ BF00199955

46. Fujisawa T, Yamaguchi Y. Autologous tumor killing activity as a prognostic factor in primary resected nonsmall cell carcinoma of the lung. Cancer (1997) 79(3):474-81. doi:10.1002/(SICI) 1097-0142(19970201)79:3<474: :AID-CNCR8>3.0.CO;2-I

47. Carter CR, Hogan BV, Cole JY, Shenoy HG, Horgan KM, Hughes TA. The expression of activating natural killer cell receptors in patients with primary breast cancer. Cancer Res (2009) 69(2 Suppl):5047. doi:10.1371/journal.pone. 0004503

48. Coffey JC, Smith MJ, Wang JH, Bouchier-Hayes D, Cotter TG, Redmond HP. Cancer surgery: risks and opportunities. Bioessays (2006) 28(4):433-7. doi:10.1002/bies.20381

49. van der Bij GJ, Oosterling SJ, Beelen RH, Meijer S, Coffey JC, van Egmond M. The perioperative period is an underutilized window of therapeutic opportunity in patients with colorectal cancer. Ann Surg (2009) 249(5):727-34. doi:10.1097/SLA.0b013e3181a3ddbd

50. Iigo M, Sakurai M, Tamura T, Saijo N, Hoshi A. In vivo antitumor activity of multiple injections of recombinant interleukin 2, alone and in combination with three different types of recombinant interferon, on various syngeneic murine tumors. Cancer Res (1988) 48(2):260-4.

51. Weese JL, Emoto SE, Sondel PM. Reduced incidence of hepatic metastases by perioperative treatment with recombinant human interleukin-2. Dis Colon Rectum (1987) 30(7):503-7. doi:10.1007/BF02554778

52. Oosterling SJ, van der Bij GJ, Mels AK, Beelen RH, Meijer S, van Egmond M, et al. Perioperative IFN-alpha to avoid surgically induced immune suppression in colorectal cancer patients. Histol Histopathol (2006) 21(7):753-60.

53. Nichols PH, Ramsden CW, Ward U, Trejdosiewicz LK, Ambrose NS, Primrose JN. Peri-operative modulation of cellular immunity in patients with colorectal cancer. Clin Exp Immunol (1993) 94(1):4-10. doi:10.1111/j.1365-2249.1993. tb05968.x

54. Klatte T, Ittenson A, Rohl FW, Ecke M, Allhoff EP, Bohm M. Perioperative immunomodulation with interleukin-2 in patients with renal cell carcinoma: results of a controlled phase II trial. Br J Cancer (2006) 95(9):1167-73. doi:10.1038/sj.bjc.6603391

55. Bohm M, Ittenson A, Schierbaum KF, Rohl FW, Ansorge S, Allhoff EP. Pretreatment with interleukin-2 modulates peri-operative immuno-dysfunction in patients with renal cell carcinoma. Eur Urol (2002) 41(4):458-67; discussion 67-8. doi:10.1016/S0302-2838(02)00031-3

56. Nichols PH, Ramsden CW, Ward U, Sedman PC, Primrose JN. Perioperative immunotherapy with recombinant interleukin 2 in patients undergoing surgery for colorectal cancer. Cancer Res (1992) 52(20):5765-9.

57. Brivio F, Lissoni P, Alderi G, Barni S, Lavorato F, Fumagalli L. Preoperative interleukin-2 subcutaneous immunotherapy may prolong the survival time in advanced colorectal cancer patients. Oncology (1996) 53(4):263-8. doi:10.1159/000227571

58. Brivio F, Fumagalli L, Lissoni P, Nardone A, Nespoli L, Fattori L, et al. Pre-operative immunoprophylaxis with interleukin-2 may improve prognosis in radical surgery for colorectal cancer stage B-C. Anticancer Res (2006) 26(1B):599-603.

59. Lin CY, Bai DJ, Yuan HY, Wang K, Yang GL, Hu MB, et al. Perioperative cimetidine administration promotes peripheral blood lymphocytes and tumor infiltrating lymphocytes in patients with gastrointestinal cancer: results of a randomized controlled clinical trial. World J Gastroenterol (2004) 10(1):136-42.

60. Li Y, Yang GL, Yuan HY, Bai DJ, Wang K, Lin CR, et al. Effects of perioperative cimetidine administration on peripheral blood lymphocytes and tumor 
infiltrating lymphocytes in patients with gastrointestinal cancer: results of a randomized controlled clinical trial. Hepatogastroenterology (2005) 52(62): 504-8.

61. Schink M, Troger W, Dabidian A, Goyert A, Scheuerecker H, Meyer J, et al. Mistletoe extract reduces the surgical suppression of natural killer cell activity in cancer patients. a randomized phase III trial. Forsch Komplementmed (2007) 14(1):9-17. doi:10.1159/000098135

62. Enesel MB, Acalovschi I, Grosu V, Sbarcea A, Rusu C, Dobre A, et al. Perioperative application of the Viscum album extract Isorel in digestive tract cancer patients. Anticancer Res (2005) 25(6C):4583-90.

63. Mels AK, Statius Muller MG, van Leeuwen PA, von Blomberg BM, Scheper RJ, Cuesta MA, et al. Immune-stimulating effects of low-dose perioperative recombinant granulocyte-macrophage colony-stimulating factor in patients operated on for primary colorectal carcinoma. Br J Surg (2001) 88(4):539-44. doi:10.1046/j.1365-2168.2001.01722.x

64. Dokun AO, Kim S, Smith HR, Kang HS, Chu DT, Yokoyama WM. Specific and nonspecific NK cell activation during virus infection. Nat Immunol (2001) 2(10):951-6. doi:10.1038/ni714

65. Natuk RJ, Welsh RM. Accumulation and chemotaxis of natural killer/large granular lymphocytes at sites of virus replication. J Immunol (1987) 138(3):877-83.

66. Diaz RM, Galivo F, Kottke T, Wongthida P, Qiao J, Thompson J, et al. Oncolytic immunovirotherapy for melanoma using vesicular stomatitis virus. Cancer Res (2007) 67(6):2840-8. doi:10.1158/0008-5472.CAN-06-3974

67. Drake CG. Prostate cancer as a model for tumour immunotherapy. Nat Rev Immunol (2010) 10(8):580-93. doi:10.1038/nri2817

68. Gujar SA, Pan DA, Marcato P, Garant KA, Lee PW. Oncolytic virus-initiated protective immunity against prostate cancer. Mol Ther (2011) 19(4):797-804. doi:10.1038/mt.2010.297

69. Miller CG, Fraser NW. Requirement of an integrated immune response for successful neuroattenuated HSV-1 therapy in an intracranial metastatic melanoma model. Mol Ther (2003) 7(6):741-7. doi:10.1016/S1525-0016(03)00120-5

70. Jarahian M, Watzl C, Fournier P, Arnold A, Djandji D, Zahedi S, et al. Activation of natural killer cells by newcastle disease virus hemagglutinin-neuraminidase. J Virol (2009) 83(16):8108-21. doi:10.1128/JVI.00211-09

71. Rintoul JL, Lemay CG, Tai LH, Stanford MM, Falls TJ, de Souza CT, et al. ORFV: a novel oncolytic and immune stimulating parapoxvirus therapeutic. Mol Ther (2012) 20(6):1148-57. doi:10.1038/mt.2011.301

72. Krebs P, Barnes MJ, Lampe K, Whitley K, Bahjat KS, Beutler B, et al. NK-cellmediated killing of target cells triggers robust antigen-specific T-cell-mediated and humoral responses. Blood (2009) 113(26):6593-602. doi:10.1182/blood2009-01-201467

73. Brun J, McManus D, Lefebvre C, Hu K, Falls T, Atkins $\mathrm{H}$, et al. Identification of genetically modified Maraba virus as an oncolytic rhabdovirus. Mol Ther (2010) 18(8):1440-9. doi:10.1038/mt.2010.103

74. Zhang J, Tai LH, Ilkow CS, Alkayyal AA, Ananth AA, de Souza CT, et al. Maraba MG1 virus enhances natural killer cell function via conventional dendritic cells to reduce postoperative metastatic disease. Mol Ther (2014) 22(7):1320-32. doi:10.1038/mt.2014.60

75. Martinez J, Huang X, Yang Y. Direct TLR2 signaling is critical for NK cell activation and function in response to vaccinia viral infection. PLoS Pathog (2010) 6(3):e1000811. doi:10.1371/journal.ppat.1000811

76. Liu C, Yu S, Kappes J, Wang J, Grizzle WE, Zinn KR, et al. Expansion of spleen myeloid suppressor cells represses NK cell cytotoxicity in tumor-bearing host. Blood (2007) 109(10):4336-42. doi:10.1182/blood-2006-09-046201

77. Cheng P, Corzo CA, Luetteke N, Yu B, Nagaraj S, Bui MM, et al. Inhibition of dendritic cell differentiation and accumulation of myeloid-derived suppressor cells in cancer is regulated by S100A9 protein. J Exp Med (2008) 205(10):2235-49. doi:10.1084/jem.20080132

78. Mazzoni A, Bronte V, Visintin A, Spitzer JH, Apolloni E, Serafini P, et al. Myeloid suppressor lines inhibit $\mathrm{T}$ cell responses by an NO-dependent mechanism. J Immunol (2002) 168(2):689-95. doi:10.4049/jimmunol.168.2.689

79. Gabrilovich DI, Nagaraj S. Myeloid-derived suppressor cells as regulators of the immune system. Nat Rev Immunol (2009) 9(3):162-74. doi:10.1038/nri2506

80. Li H, Han Y, Guo Q, Zhang M, Cao X. Cancer-expanded myeloid-derived suppressor cells induce anergy of NK cells through membrane-bound TGF-beta 1. J Immunol (2009) 182(1):240-9. doi:10.4049/jimmunol.182.1.240
81. Bridle BW, Hanson S, Lichty BD. Combining oncolytic virotherapy and tumour vaccination. Cytokine Growth Factor Rev (2010) 21(2-3):143-8. doi:10.1016/j. cytogfr.2010.02.009

82. Bridle BW, Stephenson KB, Boudreau JE, Koshy S, Kazdhan N, Pullenayegum E, et al. Potentiating cancer immunotherapy using an oncolytic virus. Mol Ther (2010) 18(8):1430-9. doi:10.1038/mt.2010.98

83. Pol JG, Zhang L, Bridle BW, Stephenson KB, Resseguier J, Hanson S, et al. Maraba virus as a potent oncolytic vaccine vector. Mol Ther (2014) 22(2):420-9. doi:10.1038/mt.2013.249

84. Bridle BW, Clouthier D, Zhang L, Pol J, Chen L, Lichty BD, et al. Oncolytic vesicular stomatitis virus quantitatively and qualitatively improves primary CD8 T-cell responses to anticancer vaccines. Oncoimmunology (2013) 2(8):e26013. doi:10.4161/onci.26013

85. Bridle BW, Boudreau JE, Lichty BD, Brunelliere J, Stephenson K, Koshy S, et al. Vesicular stomatitis virus as a novel cancer vaccine vector to prime antitumor immunity amenable to rapid boosting with adenovirus. Mol Ther (2009) 17(10):1814-21. doi:10.1038/mt.2009.154

86. Zhang L, Bridle BW, Chen L, Pol J, Spaner D, Boudreau JE, et al. Delivery of viral-vectored vaccines by $B$ cells represents a novel strategy to accelerate CD8(+) T-cell recall responses. Blood (2013) 121(13):2432-9. doi:10.1182/ blood-2012-06-438481

87. Kianizad K, Marshall LA, Grinshtein N, Bernard D, Margl R, Cheng S, et al. Elevated frequencies of self-reactive $\mathrm{CD} 8+\mathrm{T}$ cells following immunization with a xenoantigen are due to the presence of a heteroclitic CD4+ T-cell helper epitope. Cancer Res (2007) 67(13):6459-67. doi:10.1158/0008-5472.CAN-064336

88. Lane C, Leitch J, Tan X, Hadjati J, Bramson JL, Wan Y. Vaccination-induced autoimmune vitiligo is a consequence of secondary trauma to the skin. Cancer Res (2004) 64(4):1509-14. doi:10.1158/0008-5472.CAN-03-3227

89. Grinishtein N, Ventresca M, Margl R, Bernard D, Yang TC, Millar JB, et al. High-dose chemotherapy augments the efficacy of recombinant adenovirus vaccines and improves the therapeutic outcome. Cancer Gene Ther (2009) 16(4):338-50. doi:10.1038/cgt.2008.89

90. Melcher A, Parato K, Rooney CM, Bell JC. Thunder and lightning: immunotherapy and oncolytic viruses collide. Mol Ther (2011) 19(6):1008-16. doi:10.1038/mt.2011.65

91. ClinicalTrials.gov. NCT01329809: A Phase IIa Study of Neoadjuvant JX-594 (Thymidine Kinase-Deactivated Vaccinia Virus Plus GM-CSF) Administered by Intravenous Infusion or Intratumoral Injection Followed by Surgical Resection in Patients With Metastatic Colorectal Tumors Within the Liver. National Institutes of Health.

92. Adair RA, Roulstone V, Scott KJ, Morgan R, Nuovo GJ, Fuller M, et al. Cell carriage, delivery, and selective replication of an oncolytic virus in tumor in patients. Sci Transl Med (2012) 4(138):138ra77. doi:10.1126/scitranslmed. 3003578

93. Markert JM, Liechty PG, Wang W, Gaston S, Braz E, Karrasch M, et al. Phase Ib trial of mutant herpes simplex virus G207 inoculated pre-and post-tumor resection for recurrent GBM. Mol Ther (2009) 17(1):199-207. doi: $10.1038 / \mathrm{mt} .2008 .228$

94. Bohle W, Schlag P, Liebrich W, Hohenberger P, Manasterski M, Moller P, et al. Postoperative active specific immunization in colorectal cancer patients with virus-modified autologous tumor-cell vaccine. First clinical results with tumor-cell vaccines modified with live but avirulent Newcastle disease virus. Cancer (1990) 66(7):1517-23. doi:10.1002/1097-0142(19901001)66:7<1517: :AID-CNCR2820660714>3.0.CO;2-I

95. Lehner B, Schlag P, Liebrich W, Schirrmacher V. Postoperative active specific immunization in curatively resected colorectal cancer patients with a virusmodified autologous tumor cell vaccine. Cancer Immunol Immunother (1990) 32(3):173-8. doi:10.1007/BF01771453

96. Liebrich W, Schlag P, Manasterski M, Lehner B, Stohr M, Moller P, et al. In vitro and clinical characterisation of a Newcastle disease virus-modified autologous tumour cell vaccine for treatment of colorectal cancer patients. Eur J Cancer (1991) 27(6):703-10. doi:10.1016/0277-5379(91)90170-I

97. Ockert D, Schirrmacher V, Beck N, Stoelben E, Ahlert T, Flechtenmacher J, et al. Newcastle disease virus-infected intact autologous tumor cell vaccine for adjuvant active specific immunotherapy of resected colorectal carcinoma. Clin Cancer Res (1996) 2(1):21-8. 
98. Pomer S, Schirrmacher V, Thiele R, Lohrke H, Brkovic D, Staehler G. Tumor response and 4 year survival-data of patients with advanced renal-cell carcinoma treated with autologous tumor vaccine and subcutaneous R-IL-2 and IFN-alpha(2b). Int J Oncol (1995) 6(5):947-54.

99. Schirrmacher V. Clinical trials of antitumor vaccination with an autologous tumor cell vaccine modified by virus infection: improvement of patient survival based on improved antitumor immune memory. Cancer Immunol Immunother (2005) 54(6):587-98. doi:10.1007/s00262-004-0602-0

100. Tai LH, Zhang J, Auer RC. Preventing surgery-induced NK cell dysfunction and cancer metastases with influenza vaccination. Oncoimmunology (2013) 2(11):e26618. doi:10.4161/onci.26618

101. Tai LH, Zhang J, Scott KJ, de Souza CT, Alkayyal AA, Ananth AA, et al. Perioperative influenza vaccination reduces postoperative metastatic disease by reversing surgery-induced dysfunction in natural killer cells. Clin Cancer Res (2013) 19(18):5104-15. doi:10.1158/1078-0432.CCR-13-0246

102. Kottke T, Chester J, Ilett E, Thompson J, Diaz R, Coffey M, et al. Precise scheduling of chemotherapy primes VEGF-producing tumors for successful systemic oncolytic virotherapy. Mol Ther (2011) 19(10):1802-12. doi:10.1038/mt.2011.147

103. Kottke T, Hall G, Pulido J, Diaz RM, Thompson J, Chong H, et al. Antiangiogenic cancer therapy combined with oncolytic virotherapy leads to regression of established tumors in mice. J Clin Invest (2010) 120(5):1551-60. doi:10. 1172/JCI41431
104. Heo J, Breitbach CJ, Moon A, Kim CW, Patt R, Kim MK, et al. Sequential therapy with JX-594, a targeted oncolytic poxvirus, followed by sorafenib in hepatocellular carcinoma: preclinical and clinical demonstration of combination efficacy. Mol Ther (2011) 19(6):1170-9. doi:10.1038/mt.2011.39

Conflict of Interest Statement: The authors declare that the research was conducted in the absence of any commercial or financial relationships that could be construed as a potential conflict of interest.

Received: 16 June 2014; paper pending published: 07 July 2014; accepted: 30 July 2014; published online: 12 August 2014.

Citation: Tai L-H and Auer $R$ (2014) Attacking postoperative metastases using perioperative oncolytic viruses and viral vaccines. Front. Oncol. 4:217. doi: 10.3389/fonc.2014.00217

This article was submitted to Tumor Immunity, a section of the journal Frontiers in Oncology.

Copyright (C) 2014 Tai and Auer. This is an open-access article distributed under the terms of the Creative Commons Attribution License (CC BY). The use, distribution or reproduction in other forums is permitted, provided the original author(s) or licensor are credited and that the original publication in this journal is cited, in accordance with accepted academic practice. No use, distribution or reproduction is permitted which does not comply with these terms. 